\title{
Functional Implications of the CLOCK 3111T/C Single-Nucleotide Polymorphism
}

\author{
Angela R. Ozburn $1,2,3 * t$, Kush Purohit ${ }^{1 \dagger}$, Puja K. Parekh ${ }^{1}$, Gabrielle N. Kaplan ${ }^{1}$, \\ Edgardo Falcon ${ }^{4}$, Shibani Mukherjee ${ }^{5}$, Hannah M. Cates ${ }^{5,6}$ and Colleen A. McClung ${ }^{1}$ \\ ${ }^{1}$ Department of Psychiatry and Translational Neuroscience Program, University of Pittsburgh School of Medicine, Pittsburgh, \\ PA, USA, ${ }^{2}$ Department of Behavioral Neuroscience, Oregon Health \& Science University, Portland, OR, USA, ${ }^{3}$ Portland \\ Alcohol Research Center, VA Medical Center, Portland, OR, USA, ${ }^{4}$ Department of Pharmacology, University of Pennsylvania, \\ Philadelphia, PA, USA, ${ }^{5}$ Department of Psychiatry, University of Texas Southwestern Medical Center, Dallas, TX, USA, \\ ${ }^{6}$ Fishberg Department of Neuroscience, Icahn School of Medicine at Mount Sinai, New York, NY, USA
}

OPEN ACCESS

Edited by:

Stephanie Perreau-Lenz, SRI International, USA

Reviewed by:

Chamindi Seneviratne, University of Maryland Baltimore,

USA

Jerome Menet,

Texas A\&M University, USA

*Correspondence: Angela R. Ozburn ozburn@ohsu.edu

${ }^{+}$Angela R. Ozburn and Kush Purohit contributed equally.

Specialty section: This article was submitted to Addictive Disorders, a section of the journal Frontiers in Psychiatry

Received: 09 October 2015 Accepted: 04 April 2016

Published: 21 April 2016

Citation:

Ozburn AR, Purohit K, Parekh PK, Kaplan GN, Falcon E, Mukherjee S, Cates HM and McClung CA (2016) Functional Implications of the CLOCK 3111T/C Single-Nucleotide Polymorphism.

Front. Psychiatry 7:67. doi: 10.3389/fpsyt.2016.00067
Circadian rhythm disruptions are prominently associated with bipolar disorder (BD). Circadian rhythms are regulated by the molecular clock, a family of proteins that function together in a transcriptional-translational feedback loop. The CLOCK protein is a key transcription factor of this feedback loop, and previous studies have found that manipulations of the Clock gene are sufficient to produce manic-like behavior in mice (1). The CLOCK $3111 \mathrm{~T} / \mathrm{C}$ single-nucleotide polymorphism (SNP; rs1801260) is a genetic variation of the human CLOCK gene that is significantly associated with increased frequency of manic episodes in BD patients (2). The 3111T/C SNP is located in the $3^{\prime}$-untranslated region of the CLOCK gene. In this study, we sought to examine the functional implications of the human CLOCK 3111T/C SNP by transfecting a mammalian cell line (mouse embryonic fibroblasts isolated from Clock ${ }^{-1-}$ knockout mice) with pcDNA plasmids containing the human CLOCK gene with either the T or C SNP at position 3111. We then measured circadian gene expression over a 24-h time period. We found that the CLOCK3111C SNP resulted in higher mRNA levels than the CLOCK 3111T SNP. Furthermore, we found that Per2, a transcriptional target of CLOCK, was also more highly expressed with CLOCK $3111 \mathrm{C}$ expression, indicating that the $3^{\prime}$-UTR SNP affects the expression, function, and stability of CLOCK mRNA.

Keywords: circadian, clock, single-nucleotide polymorphism, gene expression, bipolar disorder, cell culture

\section{INTRODUCTION}

Bipolar disorder (BD) is a severe and chronic psychiatric disease that afflicts approximately $1-3 \%$ of the United States population (3). BD incurs substantial societal burdens, including a devastating global cost of illness primarily due to patients' lower level of functioning, greater severity of disability, longer duration of illness, and ultimately greater loss in productivity when compared patients with other mood disorders $(4,5)$. BD therapies currently in use include mood stabilizers, such as lithium and valproate; however, these are effective for only a portion of patients (6). The underlying cause of $\mathrm{BD}$ is unknown, though there is a growing body of evidence linking disruptions in circadian rhythms with the disease (7). 
Disruption of sleep and circadian rhythms are common to many psychiatric disorders, including $\mathrm{BD}$, which presents with severe circadian rhythm disruptions as a prominent symptom. It has been shown that in individuals with $\mathrm{BD}$, mood episodes are affected by light and also follow seasonal patterns $(6,8-10)$. In addition to fluctuations in mood, BD patients typically exhibit irregularities in important physiological processes that are largely regulated by the body's circadian rhythms (such as sleep, diurnal activity, body temperature, and blood pressure cycles). Mood stabilizers, such as lithium, are known to restore some of these disrupted rhythms in BD patients by producing a strong phasedelay in rhythms and increasing rhythmic amplitude, which may be very important for their observed therapeutic effects (11-17).

Circadian rhythms are regulated by a molecular clock, which consists of several core "clock" genes (e.g., Clock, Npas2, Bmal1, Per1, and Per2) that are expressed throughout the body. These elements interact with each other through a series of transcriptional and translational feedback loops that are regulated over a 24-h period in the absence of environmental input (18). Within the suprachiasmatic nucleus (SCN) and other regions, circadian rhythms are controlled by the molecular clockwork, which comprises a series of autoregulatory transcriptional-translational feedback loops. The transcription factors CLOCK or NPAS2 heterodimerize with BMAL1 and regulate the transcription of target genes, including the Period (Per) and Cryptochrome (Cry) genes, which act to inhibit the activity of the CLOCK/BMAL1 complex. Several pre-clinical studies have identified an important role for circadian genes in mood-related behaviors. Recent human genetic studies have linked elements of the molecular clock to $\mathrm{BD}$. Polymorphisms in CLOCK and other circadian genes have been found to be associated with various aspects of BD (19-25). In addition, rhythm disruptions and sleep disturbances often precipitate manic or depressive episodes (26). By studying molecular mechanisms that may underlie such BD symptoms, we can gain a better understanding of its causes and how to most effectively treat patients with this crippling disease.

The importance of circadian genes in BD has been suggested by several human genetic studies that have identified significant associations between mutations or polymorphisms of circadian genes and $\mathrm{BD}$. The Per genes, which act as key repressors of the circadian transcriptional-translational feedback loop in humans, have been found to associate with mood disorders and their age of onset $(27,28)$. Recent genome-wide association studies (GWAS) have also implicated circadian modulators, such as ARNTL and $D E C 1$, as significantly associated with BD (29). These results are particularly important given that data from family and twin studies that have established BD's genetic heritability as up to $85 \%$, suggesting a strong genetic component (30). Here, we investigate the role of a single-nucleotide polymorphism (SNP) in one circadian gene, CLOCK, that has been associated with BD (2). Interestingly, the CLOCK $3111 \mathrm{~T} / \mathrm{C}$ SNP is a genetic variant of the human CLOCK gene that has been associated with bipolar mania in BD patients. Specifically, this $\mathrm{T} \rightarrow \mathrm{C}$ polymorphism ( $\mathrm{rs} 1801260$ ) associates with increased actimetric and sleep disturbances and incidences of manic episodes in bipolar patients $(2,31,32)$. The prevalence of the $3111 \mathrm{C}$ has been reported to be between 19 and $21 \%$ in American populations (33). BD patients carrying the 3111C allele experience higher rates of insomnia and sleep disturbances, and differences between the 3111C and 3111T allele carriers were attenuated with ongoing chronic lithium treatment (32). No research group, however, has yet sought to determine the molecular mechanism through which this SNP can affect individuals with $\mathrm{BD}$. The $3111 \mathrm{~T} / \mathrm{C}$ SNP is located within the CLOCK gene's $3^{\prime}$-untranslated region ( $3^{\prime}$-UTR). The $3^{\prime}$-UTR is a region that has been shown to be very important for mRNA stability and modifications to this region can lead to either increased stability or degradation of gene products $(34,35)$.

Moreover, preclinical studies have shown that manipulations of the circadian gene, Clock, are sufficient to produce a behavioral phenotype sharing several features with bipolar mania. Mice with a dominant-negative Clock gene mutation exhibit a manic-like phenotype, including hyperactivity, reduced anxiety and depressionlike behaviors, and increased drug and alcohol intake (1, 36-38). Similar to human BD patients, these mutant mice are responsive to chronic lithium, as well as valproate treatment $(39,40)$.

Together, these results have led us to hypothesize that the 3111C SNP in the CLOCK gene decreases Clock mRNA and/ or protein levels, and that this could be a possible mechanism through which this polymorphism can affect mood in individuals with BD. In this study, we investigated the effects of the human 3111 T/C SNP on CLOCK mRNA in a mammalian cell line by examining the differences between the $3111 \mathrm{~T}$ and $3111 \mathrm{C}$ variants of $C L O C K$.

\section{MATERIALS AND METHODS}

\section{Plasmid Construction}

The pBluescript II plasmid containing the full human CLOCK gene (product i.d. ORK00509, Kazusa), was digested with Apa1 and Not1 restriction enzymes. The DNA fragment containing the CLOCK gene was isolated using agarose gel electrophoresis and the QIAQuick gel purification kit (catalog no. 28704, QIAGEN). The 5kb CLOCK containing fragment was ligated into the pcDNA3.1(-) plasmid (catalog no. V795-20, Invitrogen) digested with Apa1 and Not1 restriction enzyme sites ( $5^{\prime}$ end and $3^{\prime}$ end, respectively) and treated with calf intestinal phosphatase to prevent self-ligation. The ligated plasmids were transformed into One-Shot TOP10 Chemically Competent Escherichia coli cells (catalog no. C4040-10, Invitrogen). We performed sitedirected mutagenesis of the CLOCK construct at the site of the 3111T/C SNP using the Quikchange II XL Site-Directed Kit (catalog no. 200521, Agilent) to perform a $\mathrm{C}$ to $\mathrm{T}$ transformation, creating a $3111 \mathrm{~T}$ version of the CLOCK gene $3^{\prime}$-UTR (forward primer: 5'-GAGGTGATCATAGGGGCATAGCCAG TTCTGACAGTG-3', reverse primer: 5'-CACTGTCA GAACT GGCTATGCCCCTATGATCACCTC-3'). The full construct was verified through a series of restriction enzyme digests and complete sequencing of the CLOCK gene (including cloning junctions) by the University of Pittsburgh Genomics and Proteomics Core Laboratories. Isolated and sequence-verified clones were grown in E. coli and plasmids were isolated using QIAGEN's QIAprep Spin Miniprep kit (catalog no. 27104) and endonuclease-free Plasmid Maxi Kit (catalog no. 12162). 


\section{shRNA Construction}

A small hairpin RNA (shRNA) was constructed against the Npas 2 gene by selecting a 24 base sequence (5'-GAACACTGGATTCTTCCTGTTAAC-3') in the $3^{\prime}$-UTR (41). For the scrambled (Scr) shRNA, a random sequence of 24 bases (5'-CGGAATTTAGTTACGGGGATCCAC-3') that had no sequence similarities with any known genes/ mRNA was used (42). An anti-sense sequence of the selected mRNA region followed by a miR23 loop of 10 nucleotides (CTTCCTGTCA) was added at the $5^{\prime}$ end of the above sequences. The miR23 loop facilitates the transfer of the hairpin RNA out of the nucleus. These shRNAs were designed as synthetic duplexes with overhang ends identical to those created by SapI and XbaI restriction enzyme digestion. The annealed oligonucleotides were cloned into the adenoassociated virus (AAV) plasmid expressing enhanced green fluorescent protein (GFP) (catalog no. 240075, Agilent Technologies).

\section{Preparation of Mouse Embryonic Fibroblasts}

Mouse embryonic fibroblasts (MEFs) were isolated and prepared from homozygous Clock knockout (KO) mice at 13-14 day post-coitum (Jackson Labs, Bar Harbor, ME, USA, stock\#010925) (43). All experiments were approved by the Institutional Animal Care and Use Committee and adhered to NIH Guidelines. Clock KO MEFs were used to avoid confounds of endogenous Clock gene expression when measuring expression levels in MEFs transfected with the $3111 \mathrm{~T} / \mathrm{C}$ constructs. Briefly, uterine horns were dissected, and embryos were individually separated. The head and red organs were removed before the embryos were finely minced using a sterile razor blade. Minced tissue was treated with $0.05 \%$ Trypsin-EDTA (Gibco, Invitrogen) and DNase I (USB), and incubated for $15 \mathrm{~min}$ at $37^{\circ} \mathrm{C}$. Cells were centrifuged at $600 \times g$ for $5 \mathrm{~min}$, and supernatant was carefully removed before resuspending the MEF cell pellet in a warm solution of media containing highglucose Dulbecco's modified Eagle medium (DMEM) with L-glutamine (catalog no. 11965-084, GIBCO), supplemented with 10\% FBS (catalog no. 16000-044, GIBCO), 100 units/ $\mathrm{ml}$ penicillin, 100 units $/ \mathrm{ml}$ streptomycin, and $1 \mathrm{mM}$ sodium pyruvate (catalog no. 11360-070, GIBCO). MEFs were stored at $-80^{\circ} \mathrm{C}$.

\section{Cell Culture and Plasmid Transfection}

Mouse embryonic fibroblast cells were cultured at $37^{\circ} \mathrm{C}$ with $5 \%$ $\mathrm{CO}_{2}$ in high-glucose DMEM with L-glutamine, supplemented with $10 \%$ FBS, 100 units/ml penicillin, 100 units/ml streptomycin, and $1 \mathrm{mM}$ sodium pyruvate. Cells were grown to $80-100 \%$ confluence before being split using $0.25 \%$ Trypsin-EDTA with phenol red (catalog no. 25200-056, GIBCO). MEFs were transfected with plasmid construct(s) using Lipofectamine LTX (catalog no. 15338-100, Invitrogen) and Opti-MEM I Reduced Media Serum (catalog no. 31985-062, Invitrogen) according to the manufacturer's instructions. Following transfections, cells were collected for RNA isolation and quantitative RT-PCR.

\section{RNA Isolation and cDNA Synthesis}

Approximately, $1 \times 10^{5}$ cells were transfected with $2 \mu \mathrm{g}$ of the $3111 \mathrm{~T}$ or $3111 \mathrm{C}$ versions of the CLOCK SNP. Seventy-two hours following transfection with expression constructs, cells were selected using $100 \mu \mathrm{g} / \mathrm{ml}$ Geneticin Selective Antibiotic (catalog no. 10131-035, GIBCO) to generate stable lines. After selection, RNA from the MEFs was isolated using TRIzol reagent (catalog no. 15596-026, Ambion), according to the manufacturer's instructions. Briefly, cells were treated with TRIzol reagent and chloroform, and RNA was isolated with the addition of the carrier glycogen, followed by precipitation in isopropanol and centrifugation. Seventy-five percent ethanol was used to wash the RNA pellet, which was re-suspended in nuclease-free $\mathrm{H}_{2} \mathrm{O}$. Total RNA (200 ng) was treated with DNase I (Catalog no. 18068-015, Invitrogen), and then reverse-transcribed to cDNA using the SuperScript III First-Strand Synthesis System (catalog no. 18080051, Invitrogen) according to manufacturer's protocols.

\section{Quantitative Real-Time PCR}

Real-time quantitative polymerase chain reaction (RT-PCR) was completed using the 7900HT Fast Real-Time PCR System (catalog no. 4329003, Applied Biosystems). cDNA samples were prepared with the PowerSYBRGreen qPCRMasterMix (catalogno.4367659, Applied Biosystems) along with oligo primers for $h C L O C K$ (forward primer: 5'-ATGGGCCAGGTGGTGACTGCAT-3', reverse primer: 5'-TGACCCAGCCACCGCAACAAT-3'), G418-resistance gene present in pcDNA3.1(-) (forward primer: 5'-CGCATGATTGAACAAGATGGATTGC-3', reverse primer: $5^{\prime}$-GTTCATTCAGGGCACCGGACA-3'), and mPer2 (forward primer 5'-GAGTGTGTGCAGCGGCTTAG-3', reverse primer $5^{\prime}$-GTAGGGTGTCATGCGGAAGG-3'). PCRs were run in duplicate, followed by a dissociation reaction, and were subjected to agarose gel electrophoresis to determine specificity of the amplified product. Gene expression was quantified using the $\Delta \mathrm{CT}$ (CT $=$ cycle threshold $)$ method as previously described (44). Gel electrophoresis of the samples was then performed in order to further confirm the correct size of the amplified PCR products. Efficiencies of qPCR primers used in this study were calculated by means of construction of a standard curve as previously described (45). Samples of experimental MEF cDNA were serially diluted and prepared with the Power SYBR Green qPCR Master Mix (catalog no. 4367659, Applied Biosystems). Dilution series from 1:1 to 1:64 were used for transfected genes ( $h C L O C K$, G418-resistance gene), while dilution series from 1:1 to 1:8 were used for endogenous genes (mPer2, Npas2). qPCRs were run in duplicate and followed by a dissociation reaction. Gene expression was quantified using the $\Delta \mathrm{CT}$ method and plotted against the logarithm of the dilution factor. The calculated efficiencies for the primer sets used are as follows: $h$ Clock $88 \%, G 41893 \%, m P e r 2$ $110 \%$, and Npas $278 \%$. The observed relatively low expression levels of Npas 2 indicate that CLOCK KO MEFs do not express high levels of Npas 2 to compensate for the loss of CLOCK. The $h C L O C K$ and G418 primer sets used for determination and comparison of CLOCK3111T and CLOCK3111C levels have similar efficiencies; therefore, we conclude that these findings do not affect interpretation of the data. 


\section{Circadian Gene Expression Assay}

Approximately $1 \times 10^{4}$ cells were plated in 12 -well plates, and were doubly transfected with $1 \mu \mathrm{g}$ each of pcDNA3.1(-) (containing the $3111 \mathrm{~T}, 3111 \mathrm{C}$, or no insert), and a plasmid containing Npas 2 shRNA or a Scr shRNA. A caveat of using Clock KO MEFs was that previous research has shown that KO of the Clock gene can result in increased Npas2 expression, possibly as a compensatory mechanism (46). Because, as a CLOCK homolog, NPAS2 also regulates Per2 gene expression, an Npas2 shRNA was co-transfected along with either versions of the 3111 T/C SNP when measuring Per 2 circadian gene expression in $\mathrm{qPCR}$ studies. Seventy-two hours following transfection, MEFs were subjected to serum shock to synchronize individual molecular rhythms as previously described (47). Briefly, cells were serum shocked using DMEM supplemented with 50\% horse serum for $30 \mathrm{~min}$ to induce expression of circadian genes and synchronize the molecular clock (48). After the serum shock treatment, MEFs were switched to recovery media containing high-glucose DMEM with L-glutamine supplemented with $2 \%$ B-27 (catalog no. 17504-044, GIBCO), $350 \mathrm{mg} / \mathrm{l}$ sodium bicarbonate, $0.25 \%$ penicillin/streptomycin, and $10 \mathrm{mM}$ HEPES (catalog no. 15630-106, GIBCO). Cells were collected every $3 \mathrm{~h}$ for the next $27 \mathrm{~h}$ (e.g., circadian time CT3, CT6, СT9, CT12, etc.) and processed for RNA isolation/ cDNA synthesis. Samples were then used to measure circadian gene expression (as described in Section "Quantitative RealTime PCR").

\section{Statistics}

All data are presented as the mean \pm SEM. Two-way analysis of variance (ANOVA) and Student's $t$-tests were performed to determine significant differences between experimental groups and time points. Statistical outliers were identified as $\pm 2 \times \mathrm{SD}$ of the mean and removed prior to further data analysis.

\section{RESULTS}

\section{Npas2 Gene Expression in MEF Cells and Knock-Down}

NPAS2, a homolog of CLOCK, can heterodimerize with BMAL1 and positively regulate the transcription of Per and Cry genes. Since it is possible that Npas 2 may be upregulated in Clock KO MEFs, Npas2 expression in WT and Clock KO MEFs was measured using qPCR (Figure 1A). After normalizing CT values to GAPDH, we performed a two-tailed unpaired Student's $t$-test on our preliminary data, which revealed a statistically significant difference between mean $\Delta \mathrm{CT}$ values $[n=2$, Figure $1 \mathbf{A}]$. These data show a 4.59 -cycle increase in Npas 2 expression in Clock KO MEFs compared to WT MEFs (Student's $t$-test, $P<0.05$ ). We used an shRNA to knockdown expression of Npas2. Npas 2 shRNA resulted in a decrease in Npas 2 expression as compared with Scr shRNA, as qPCR studies revealed that Npas 2 gene expression was undetected after 40 cycles of PCR in cells expressing the Npas 2 shRNA. Representative data from ZT21 is shown (Figure 1B).

\section{CLOCK 3111T/C SNP Gene Expression (Single Time Point)}

To better understand the effects of the CLOCK 3111T/C SNP on mRNA expression and stability, we transfected Clock KO MEFs with either version of the SNP and sought to measure differences in CLOCK mRNA levels between cells expressing the 3111C and $3111 \mathrm{~T}$ alleles (at a single time point). Using primers for the human CLOCK gene, our studies revealed that cells expressing the $3111 \mathrm{C}$ allele showed a 4.17 -fold increase in CLOCK mRNA levels (Student's $t$-test, $P<0.05, n=8$, Figure 2). Transfection efficiency was not directly evaluated; we used antibiotic selection to ensure proliferation of only transfected cells. Furthermore, we used the housekeeping gene, G418 (the gene in the pcDNA plasmid that is responsible for conferring antibiotic resistance to Geneticin) for calculating the dCT.

\section{Twenty-Four-Hour Gene Expression Levels of CLOCK 3111T/C and Per2}

To test the functional implications of the CLOCK 3111T/C SNP on CLOCK mRNA expression and stability over a 24-h time period, we transfected CLOCK KO MEFs with either version of the SNP and sought to determine if there were differences in CLOCK mRNA levels between cells expressing the 3111C and $3111 \mathrm{~T}$ alleles. Transfection efficiency was not directly evaluated; we used the housekeeping gene, G418 (the gene in the pcDNA plasmid that is responsible for conferring antibiotic resistance to geneticin) for calculating the dCT. Our findings show that MEFs transfected with the $3111 \mathrm{C}$ construct showed significantly increased levels of CLOCK mRNA at every time point measured, excluding CT18 ( $n=4 /$ group/timepoint, Figure 3 ). Using a twoway ANOVA, we found a highly significant SNP $\times$ time interaction; SNP $\times$ time $[F=(21,93)=5.34, P<0.0001]$. The main effect of the SNP was highly significant; $[F=(3,93)=156.45$, $P<0.0001]$, as was the main effect of time; $[F=(7,93)=16.68$, $P<0.0001]$. Bonferroni post hoc test results reveal significant differences in CLOCK expression in MEFs co-transfected with $3111 \mathrm{~T}$ or C SNP constructs (along with Npas2 shRNA; Figure 3). We were primarily interested in these group comparisons (due to the upregulation of Npas 2 in Clock KO MEFs). There were no significant differences in CLOCK expression seen in cells transfected with or without the Npas2 shRNA.

To test the CLOCK 3111T/C SNP's effects on CLOCK protein function, 24-h Per2 expression was measured in Clock KO MEFs co-transfected with the $3111 \mathrm{~T}$ or $3111 \mathrm{C}$ constructs and the Npas 2 shRNA ( $n=4 /$ group/timepoint, Figure 4 ). As a downstream transcriptional target of the CLOCK protein, Per 2 is expressed as part of a transcriptional-translational feedback loop in the molecular clock. Therefore, alterations to Per2 expression indirectly reveal differences in CLOCK's transcriptional activity between cells expressing the T or C variant of the SNP. Npas2 shRNA plasmid was co-transfected along with the human CLOCK constructs in order to eliminate the possible confound of Per2 expression driven by NPAS2. Using a two-way ANOVA, we found a significant interaction between SNP and time: SNP $\times$ time $[F=(21$, $95)=8.52, P<0.0001]$. We also found that the main effect of the SNP was highly significant; $[F=(3,95)=523.66, P<0.0001]$. 


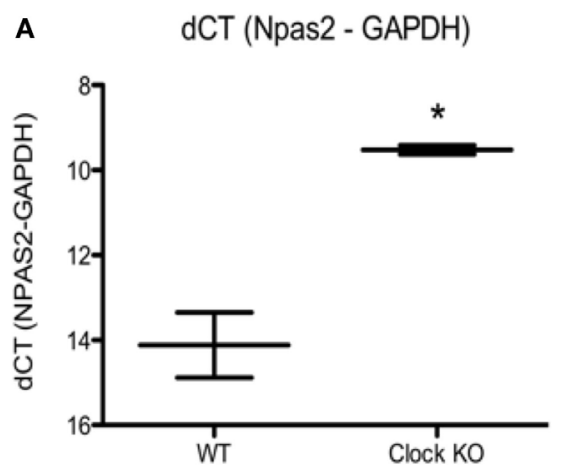

B

\begin{tabular}{|c|c|}
\hline Experimental Group & Mean CT \\
\hline Clock $3111 \mathrm{C}+$ Npas $2 \mathrm{KD}$ & Undetermined \\
Clock $3111 \mathrm{~T}+$ Npas $2 \mathrm{KD}$ & Undetermined \\
\hline Clock $311 \mathrm{C}+$ scramble & $\mathbf{3 4 . 1 2}$ \\
Clock $3111 \mathrm{~T}+$ scramble & $\mathbf{3 7 . 2 4}$ \\
\hline
\end{tabular}

FIGURE 1 | Npas2 expression in Clock KO and WT MEFs. (A) Npas2 expression is significantly increased in Clock KO MEFS. ${ }^{*} P<0.05$. (B) Npas2 shRNA results in significantly decreased Npas2 expression as compared with Scramble shRNA (representative data from CT21).

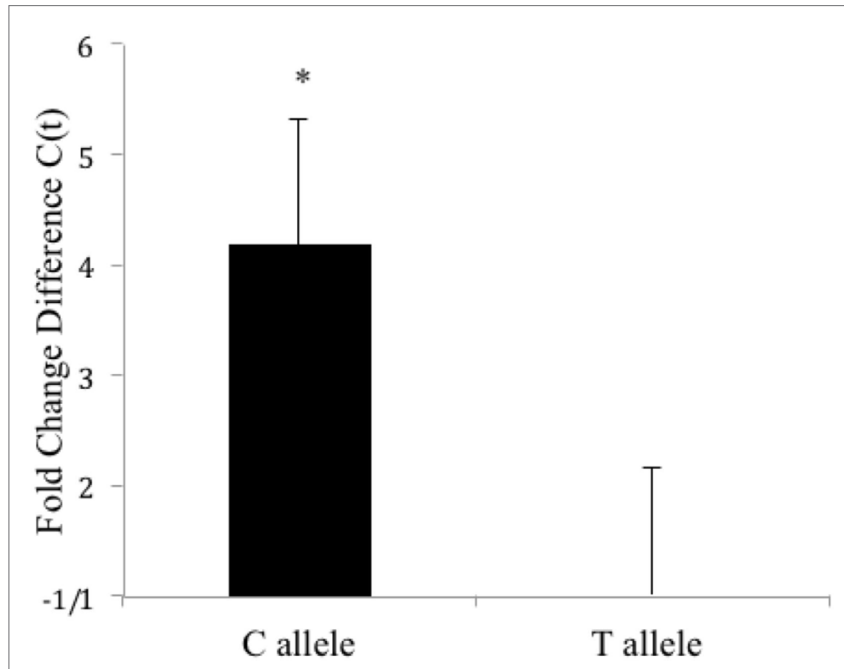

FIGURE 2 | Fold change difference in $h C L O C K$ levels in Clock3111T/C-expressing MEFs (single time point). Clock 3111C gene expression is significantly higher than $3111 \mathrm{~T}$ expression. ${ }^{*} P<0.05$.

The main effect of time was also significant; $[F=(7,95)=23.67$, $P<0.0001]$. Bonferroni post hoc testing revealed that in MEFs expressing the CLOCK $3111 \mathrm{C}$ variant and Npas 2 shRNA, expression of Per 2 mRNA is significantly increased at every time point measured.

\section{DISCUSSION}

Severe circadian rhythm disruptions are prominent symptoms in mood disorders, including BD and major depression. There is mounting pre-clinical and clinical data, suggesting that circadian genes play a role in a number of disease parameters, such as age of onset $(27,28)$. Here, we sought to study the implications of the CLOCK $3111 \mathrm{~T} / \mathrm{C}$ SNP, a polymorphism located in the $3^{\prime}$ UTR that has been shown to associate with increased frequency and severity of manic episodes and actimetric disturbances in $\mathrm{BD}$ patients $(2,31,32)$. Alterations to the $3^{\prime}$-UTR have been

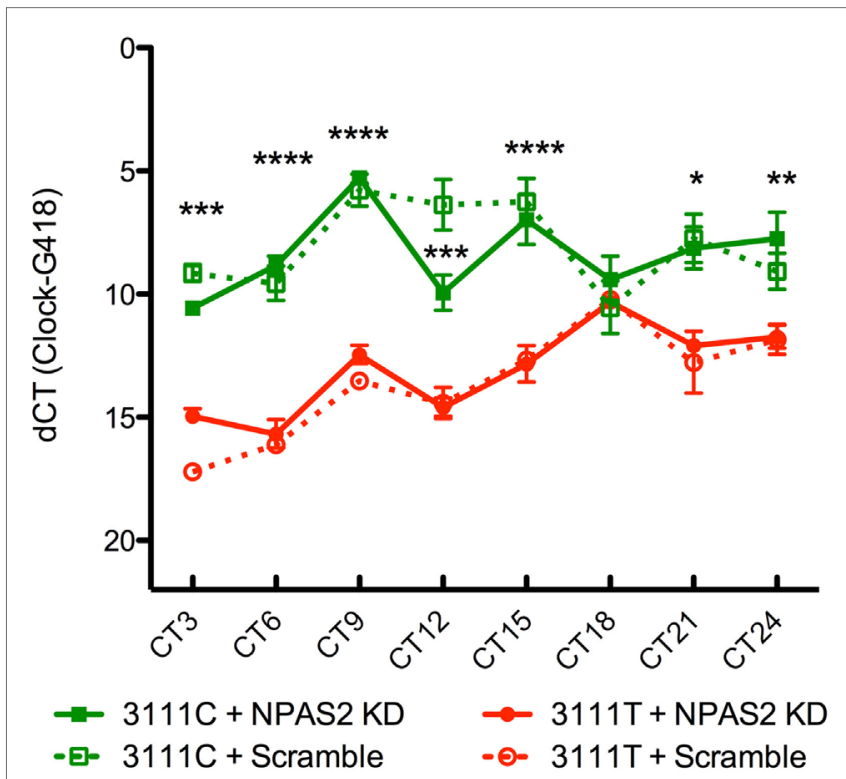

FIGURE 3 | Twenty-four-hour expression of hCLOCK in 3111T/C SNP-expressing MEFs. Clock $3111 \mathrm{C}$ gene expression over $24 \mathrm{~h}$ is significantly higher than Clock $3111 \mathrm{~T}$ expression. ${ }^{* \star *} P<0.0001$, ${ }^{\star \star \star} P<0.001,{ }^{\star \star} P<0.01,{ }^{\star} P<0.05$.

shown to engage in transcriptional and translational regulation through various pathways, including those involving mRNA stability and degradation (49). In addition, previous animal research has found that reductions in CLOCK expression or function produces increased locomotor and drug- and alcoholseeking behavior, and decreased depression- and anxiety-like behavior - hallmarks of bipolar mania (1,36-38). Therefore, we sought to test the hypothesis that the $3111 \mathrm{C}$ variant of the $3111 \mathrm{~T} / \mathrm{C}$ SNP would result in reduced CLOCK expression and alter Per2 expression (as a measure of altered CLOCK transcriptional activity) when compared to the $3111 \mathrm{~T}$ allele. Using cell culture and qPCR, we found that the $3111 \mathrm{C}$ variant results in significantly increased CLOCK and Per 2 mRNA expression over $24 \mathrm{~h}$. 


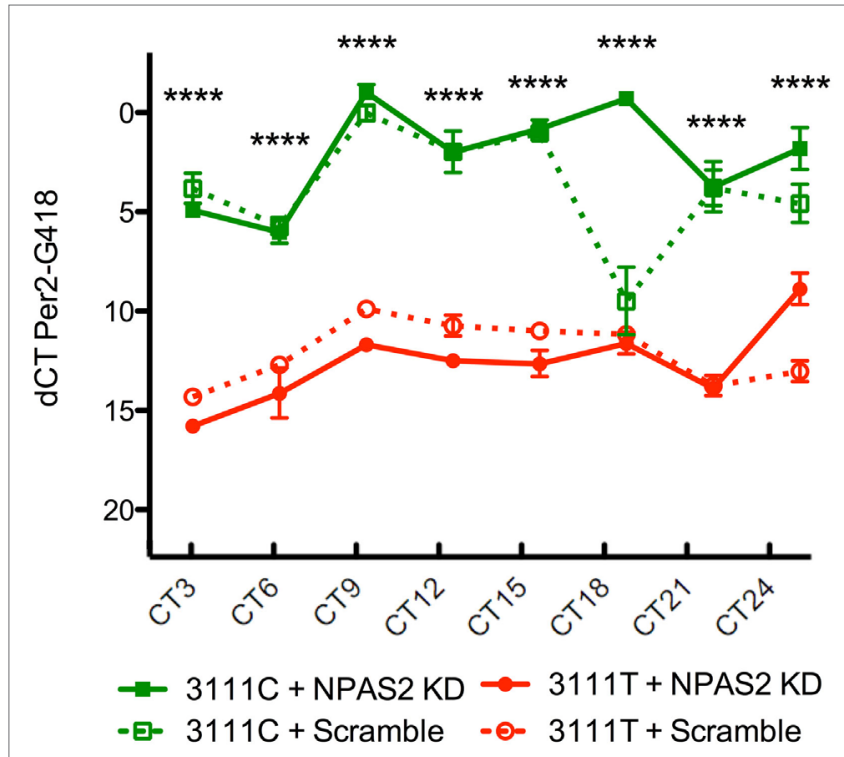

FIGURE 4 | Twenty-four-hour expression of Per2 in 3111T/C SNP-expressing MEFs. Clock3111C gene expression over $24 \mathrm{~h}$ is significantly higher than Clock3111T expression. ${ }^{* \star \star *} P<0.0001$.

These findings are very exciting as there is a clear dearth in the literature of molecular research of this SNP. The possibility that a clinically relevant SNP results in increased CLOCK expression is important to many interesting genes, including related circadian genes as well as those outside of the molecular clock. For example, in this study, we report that Per2, a gene positively regulated by CLOCK, exhibits significantly elevated expression over $24 \mathrm{~h}$ in cells expressing the CLOCK $3111 \mathrm{C}$ SNP. This suggests that CLOCK protein levels are also increased.

Changes in expression of these related circadian genes may have important implications for rhythms of critical physiological processes. Sleep/wake, hormonal, body temperature, and blood pressure rhythms, for instance, are all influenced by molecular clockwork. These changes may also be important in the understanding and development of effective treatments for mood disorders, as current therapies have been shown to strongly phase-shift circadian rhythms. For example, selective serotonin reuptake inhibitors (SSRI's) and morning-light therapy produce circadian phase shift advances in the SCN, while lithium and valproate induce phase shift delays and period-lengthening (50-54).

Outside of the molecular clock, changes in CLOCK expression may have tremendous implications for a wide variety of genes that clearly play an important role in regulating mood and behavior. Tyrosine hydroxylase (TH), dopamine receptor D3 (Drd3), cholecystokinin (CCK), and many other regulators of dopaminergic transmission are under transcriptional control by the CLOCK protein $(46,55$, 56). Additionally, mice with an induced mutation of the Clock gene, which results in overexpression of a truncated CLOCK protein with dominant-negative function, express a behavioral profile strongly resembling $\mathrm{BD}$ patients in the manic state that can be reversed using chronic lithium treatment (1). These mice show increased dopamine synthesis and dopamine firing in the ventral tegmental area (VTA), a region featuring important dopaminergic projections that have been implicated in psychiatric disorders (39). This includes an increase in TH expression in the VTA (36). Most of the manic-like behavioral phenotypes of these mutant mice are rescued with the induced expression of a functional CLOCK protein in the VTA, while knockdown of Clock expression in the VTA in wild-type mice produces a "mixed state" of reduced anxiety- but increased depression-like behavior (1, 40, 42). Taking this into consideration, it becomes easy to see how a SNP affecting Clock expression can have major functional consequences for a number of diseases.

It is still unclear as to how CLOCK mRNA levels are increased in cells expressing the $3111 \mathrm{C}$ variant. Changes in mRNA levels for $3111 \mathrm{C}$ could be due to increased stability of the mRNA. One possible mechanism to explain the increased mRNA stability is that the $3^{\prime}$-UTR hosts several regulatory elements controlling stability, one of which is binding sites for microRNAs (miRNAs). miRNAs are short, untranslated sequences of RNA that bind specific RNA sequences and, once bound, decrease mRNA transcript stability (57). The $3^{\prime}$-UTR of the CLOCK gene also features a binding site for miRNA-182 less than 40 bases from the $3111 \mathrm{~T} / \mathrm{C}$ SNP that may affect stability of the mRNA by preventing or activating degradation mechanisms. It is possible that the $3111 \mathrm{C}$ variant may interfere with this site, reducing miRNA-182 binding and thereby increasing stability and elevating levels of CLOCK mRNA.

Our studies show that the CLOCK 3111T/C SNP has important functional consequences by increasing CLOCK and Per 2 mRNA expression over $24 \mathrm{~h}$. These changes may be due to a number of different mechanisms, including miRNA-182 binding sites in the 3 '-UTR. In the future, we plan to investigate whether miRNA-182 binding is altered in the $3111 \mathrm{~T} / \mathrm{C}$ SNP. Additional future studies may focus on behavioral studies involving transgenic mice that express either version of the 3111 T/C SNP. Given that our studies report altered Per2 expression, the clinical relevance of the SNP may also be further studied by examining whether carriers of the $3111 \mathrm{C}$ allele respond differently to mood stabilizers that are known to induce changes in circadian rhythm phase and period. These results directly help to further characterize the functional implications of this clinically relevant SNP, and because the $3111 \mathrm{~T} / \mathrm{C}$ SNP is only one polymorphism of many identified for the CLOCK gene that associates with $\mathrm{BD}$, they provide a stepping off point for future SNP studies in this model.

\section{AUTHOR CONTRIBUTIONS}

$\mathrm{AO}, \mathrm{SM}$, and $\mathrm{CM}$ designed the experiments. AO, KP, PP, GK, $\mathrm{EF}, \mathrm{SM}$, and $\mathrm{HC}$ performed research; KP, AO, GK, EF, and CM analyzed data. $\mathrm{AO}, \mathrm{KP}, \mathrm{GK}$, and $\mathrm{CM}$ wrote the manuscript.

\section{ACKNOWLEDGMENTS}

We thank Elizabeth Gordon, Ariel Ketcherside, Emily Webster, and Heather Buresch for animal care and husbandry. This work was supported by a NARSAD Young Investigator Award, Veterans Affairs Career Development Award 2 IK2 BX002488, NIH DA07290, and AA020452 to AO, NIH DA028085 to EF, and NIH MH082876 and DA023988 to CM. 


\section{REFERENCES}

1. Roybal K, Theobold D, Graham A, DiNieri JA, Russo SJ, Krishnan V, et al. Mania-like behavior induced by disruption of CLOCK. Proc Natl Acad Sci U $S$ A (2007) 104(15):6406-11. doi:10.1073/pnas.0609625104

2. Benedetti F, Serretti A, Colombo C, Barbini B, Lorenzi C, Campori E, et al. Influence of CLOCK gene polymorphism on circadian mood fluctuation and illness recurrence in bipolar depression. Am J Med Genet B Neuropsychiatr Genet (2003) 123B:23-6. doi:10.1002/ajmg.b.20038

3. Kupfer DJ, Angst J, Berk M, Dickerson F, Frangou S, Frank E, et al. Advances in bipolar disorder: selected sessions from the 2011 International Conference on Bipolar Disorder. Ann N Y Acad Sci (2011) 1242(1):1-25. doi:10.1111/j.1749-6632.2011.06336.x

4. Kleine-budde K, Touil E, Moock J, Bramesfeld A, Kawohl W, Rössler W. Cost of illness for bipolar disorder: a systematic review of the economic burden. Bipolar Disord (2014) 16(4):337-53. doi:10.1111/bdi.12165

5. Pini S, de Queiroz V, Pagnin D, Pezawas L, Angst J, et al. Eur Neuropsychopharmacol (2005) 15(4):425-34.

6. McClung CA. Circadian genes, rhythms and the biology of mood disorders. Pharmacol Ther (2007) 114(2):222-32. doi:10.1016/j.pharmthera.2007.02.003

7. McClung CA. How might circadian rhythms control mood? Let me count the ways. Biol Psychiatry (2013) 74(4):242-9. doi:10.1016/j.biopsych.2013.02.019

8. Post RM. Treatment of bipolar depression: evolving recommendations. Psychiatr Clin North Am (2016) 39(1):11-33. doi:10.1016/j.psc.2015.09.001

9. Szmulewicz A, Samamé C, Caravotta P, Martino DJ, Igoa A, Hidalgo-Mazzei $\mathrm{D}$, et al. Behavioral and emotional adverse events of drugs frequently used in the treatment of bipolar disorders: clinical and theoretical implications. Int J Bipolar Disord (2016) 4(1):6. doi:10.1186/s40345-016-0047-3

10. Vieta E, Hidalgo DH. Treatment resistant bipolar depression. Eur Psychiatry (2015) 30(1):58. doi:10.1016/S0924-9338(15)30048-1

11. Atkinson M, Kripke DF, Wolf SR. Autorhythmometry in manic-depressives. Chronobiologia (1975) 2(4):325-35.

12. Dokucu ME, Yu L, Taghert PH. Lithium- and valproate-induced alterations in circadian locomotor behavior in Drosophila. Neuropsychopharmacology (2005) 30:2216-24. doi:10.1038/sj.npp.1300764

13. Gould TD, Manji HK. Glycogen synthase kinase-3: a putative molecular target for lithium mimetic drugs. Neuropsychopharmacology (2005) 30(7):1223-37.

14. Iwahana E, Akiyama M, Miyakawa K, Uchida A, Kasahara J, Fukunaga K, et al. Effect of lithium on the circadian rhythms of locomotor activity and glycogen synthase kinase-3 protein expression in the mouse suprachiasmatic nuclei. Eur J Neurosci (2004) 19(8):2281-7. doi:10.1111/j.0953-816X.2004.03322.x

15. Johnsson A, Engelmann W, Pflug B, Klemke W. Period lengthening of human circadian rhythms by lithium carbonate, a prophylactic for depressive disorders. Int J Chronobiol (1983) 8(3):129-47.

16. Klemfuss H. Rhythms and the pharmacology of lithium. Pharmacol Ther (1992) 56(1):53-78. doi:10.1016/0163-7258(92)90037-Z

17. Kripke DF, Mullaney DJ, Atkinson M, Wolf S. Circadian rhythm disorders in manic-depressives. Biol Psychiatry (1978) 13(3):335-51.

18. Takahashi JS, Shimomura K, Kumar V. Searching for genes underlying behavior: lessons from circadian rhythms. Science (2008) 322(5903):909-12. doi:10.1126/science.1158822

19. Kripke DF, Nievergelt CM, Joo E, Shekhtman T, Kelsoe JR. Circadian polymorphisms associated with affective disorders. JCircadian Rhythms (2009) 7:2. doi:10.1186/1740-3391-7-2

20. Lamont EW, Legault-Coutu D, Cermakian N, Boivin DB. The role of circadian clock genes in mental disorders. Dialogues Clin Neurosci (2007) 9(3):333-42.

21. Lamont EW, Coutu DL, Cermakian N, Boivin DB. Circadian rhythms and clock genes in psychotic disorders. Isr J Psychiatry Relat Sci (2010) 47(1):27-35.

22. Mansour HA, Wood J, Logue T, Chowdari KV, Dayal M, Kupfer DJ, et al. Association study of eight circadian genes with bipolar I disorder, schizoaffective disorder and schizophrenia. Genes Brain Behav (2006) 5(2):150-7. doi:10.1111/j.1601-183X.2005.00147.x

23. Mansour HA, Talkowski ME, Wood J, Chowdari KV, McClain L, Prasad K, et al. Association study of 21 circadian genes with bipolar I disorder, schizoaffective disorder, and schizophrenia. Bipolar Disord (2009) 11(7):701-10. doi:10.1111/j.1399-5618.2009.00756.x

24. Sjoholm LK, Backlund L, Cheteh EH, Ek IR, Frisen L, Schalling M, et al. CRY2 is associated with rapid cycling in bipolar disorder patients. PLoS One (2010) 5(9):e12632. doi:10.1371/journal.pone.0012632
25. Soria V, Martinez-Amoros E, Escaramis G, Valero J, Perez-Egea R, Garcia C, et al. Differential association of circadian genes with mood disorders: CRY1 and NPAS2 are associated with unipolar major depression and CLOCK and VIP with bipolar disorder. Neuropsychopharmacology (2010) 35(6):1279-89. doi:10.1038/npp.2009.230

26. Harvey AG. Sleep and circadian functioning: critical mechanisms in the mood disorders? Annu Rev Clin Psychol (2011) 7:297-319. doi:10.1146/ annurev-clinpsy-032210-104550

27. Benedetti F, Dallaspezia S, Colombo C, Pirovano A, Marino E, Smeraldi E. A length polymorphism in the circadian clock gene Per3 influences age at onset of bipolar disorder. Neurosci Lett (2008) 445(2):184-7. doi:10.1016/j. neulet.2008.09.002

28. Nievergelt CM, Kripke DF, Barrett TB, Burg E, Remick RA, Sadovnick AD, et al. Suggestive evidence for association of the circadian genes PERIOD3 and ARNTL with bipolar disorder. Am J Med Genet B Neuropsychiatr Genet (2006) 141B(3):234-41. doi:10.1002/ajmg.b.30252

29. McCarthy MJ, Nievergelt CM, Kelsoe JR, Welsh DK. A survey of genomic studies supports association of circadian clock genes with bipolar disorder spectrum illnesses and lithium response. PLoS One (2012) 7(2):e32091. doi:10.1371/journal.pone. 0032091

30. McGuffin P, Rijsdijk F, Andrew M, Sham P, Katz R, Cardno A. The heritability of bipolar affective disorder and the genetic relationship to unipolar depression. Arch Gen Psychiatry (2003) 60(5):497-502. doi:10.1001/archpsyc. 60.5.497

31. Benedetti F, Dallaspezia S, Fulgosi MC, Lorenzi C, Serretti A, Barbini B, et al. Actimetric evidence that CLOCK 3111 T/C SNP influences sleep and activity patterns in patients affected by bipolar depression. Am J Med Genet B Neuropsychiatr Genet (2007) 144B(5):631-5. doi:10.1002/ajmg.b.30475

32. Serretti A, Cusin C, Benedetti F, Mandelli L, Pirovano A, Zanardi R, et al. Insomnia improvement during antidepressant treatment and CLOCK gene polymorphism. Am J Med Genet B Neuropsychiatr Genet (2005) 137B(1):36-9. doi:10.1002/ajmg.b.30130

33. Desan PH, Oren DA, Malison R, Price LH, Rosenbaum J, Smoller J, et al. Genetic polymorphism at the CLOCK gene locus and major depression. Am J Med Genet (2000) 96(3):418-21. doi:10.1002/1096-8628 (20000612)96:3<418::AID-AJMG34>3.0.CO;2-S

34. Hentze MW, Kuhn LC. Molecular control of vertebrate iron metabolism: mRNA-based regulatory circuits operated by iron, nitric oxide, and oxidative stress. Proc Natl Acad Sci U S A (1996) 93:8175-82. doi:10.1073/ pnas.93.16.8175

35. Zaidi SH, Malter JS. Amyloid precursor protein mRNA stability is controlled by a 29-base element in the 3c-untranslated region. J Biol Chem (1994) 269:24007-13.

36. McClung CA, Sidiropoulou K, Vitaterna M, Takahashi JS, White FJ, Cooper DC, et al. Regulation of dopaminergic transmission and cocaine reward by the Clock gene. Proc Natl Acad Sci U S A (2005) 102(26):9377-81. doi:10.1073/ pnas. 0503584102

37. Ozburn AR, Larson EB, Self DW, McClung CA. Cocaine self-administration behaviors in Clock $\triangle 19$ mice. Psychopharmacology (Berl) (2012) 223(2):16977. doi:10.1007/s00213-012-2704-2

38. Ozburn AR, Falcon E, Mukherjee S, Gillman A, Arey R, Spencer S, et al. The role of clock in ethanol-related behaviors. Neuropsychopharmacology (2013) 38(12):2393-400. doi:10.1038/npp.2013.138

39. Coque L, Mukherjee S, Cao JL, Spencer S, Marvin M, Falcon E, et al. Specific role of VTA dopamine neuronal firing rates and morphology in the reversal of anxiety-related, but not depression-related behavior in the Clock $\Delta 19$ mouse model of mania. Neuropsychopharmacology (2011) 36(7):1478-88. doi:10.1038/npp.2011.33

40. Dzirasa K, Coque L, Sidor MM, Kumar S, Dancy EA, Takahashi JS, et al Lithium ameliorates nucleus accumbens phase-signaling dysfunction in a genetic mouse model of mania. J Neurosci (2010) 30(48):16314-23. doi:10.1523/JNEUROSCI.4289-10.2010

41. Ozburn AR, Falcon E, Twaddle A, Nugent AL, Gillman AG, Spencer SM, et al. Direct regulation of diurnal Drd3 expression and cocaine reward by NPAS2. Biol Psychiatry (2015) 77(5):425-33. doi:10.1016/j.biopsych.2014.07.030

42. Mukherjee S, Coque L, Cao JL, Kumar J, Chakravarty S, Asaithamby A, et al. Knockdown of Clock in the ventral tegmental area through RNA interference results in a mixed state of mania and depression-like behavior. Biol Psychiatry (2010) 68(6):503-11. doi:10.1016/j.biopsych.2010.04.031 
43. Jozefczuk J, Drews K, Adjaye J. Preparation of mouse embryonic fibroblast cells suitable for culturing human embryonic and induced pluripotent stem cells. J Vis Exp (2012) (64). doi:10.3791/3854

44. Tsankova NM, Kumar A, Nestler EJ. Histone modifications at gene promoter regions in rat hippocampus after acute and chronic electroconvulsive seizures. J Neurosci (2004) 24(24):5603-10. doi:10.1523/ JNEUROSCI.0589-04.2004

45. Bustin SA, Benes V, Garson JA, Hellemans J, Huggett J, Kubista M, et al. The MIQE guidelines: minimum information for publication of quantitative real-time PCR experiments. Clin Chem (2009) 55(4):611-22. doi:10.1373/ clinchem.2008.112797

46. Ozburn AR, Falcon E, Twaddle A, Nugent AL, Gillman AG, Spencer $\mathrm{SM}$, et al. Direct regulation of diurnal Drd3 expression and cocaine reward by NPAS2. Biol Psychiatry (2015) 77(5):425-33. doi:10.1016/j. biopsych.2014.07.030

47. Izumo M, Johnson CH, Yamazaki S. Circadian gene expression in mammalian fibroblasts revealed by real-time luminescence reporting: temperature compensation and damping. Proc Natl Acad Sci U S A (2003) 100(26):16089-94. doi:10.1073/pnas.2536313100

48. Balsalobre A, Damiola F, Schibler U. A serum shock induces circadian gene expression in mammalian tissue culture cells. Cell (1998) 93(6):929-37. doi:10.1016/S0092-8674(00)81199-X

49. Mignone F, Gissi C, Liuni S, Pesole G. Untranslated regions of mRNAs. Genome Biol (2002) 3(3):REVIEWS0004. doi:10.1186/ gb-2002-3-3-reviews0004

50. Dudley TE, Dinardo LA, Glass JD. In vivo assessment of the midbrain raphe nuclear regulation of serotonin release in the hamster suprachiasmatic nucleus. J Neurophysiol (1999) 81(4):1469-77.

51. Lewy AJ, Lefler BJ, Emens JS, Bauer VK. The circadian basis of winter depression. Proc Natl Acad Sci U S A (2006) 103(19):7414-9. doi:10.1073/ pnas.0602425103
52. Lewy AJ, Rough JN, Songer JB, Mishra N, Yuhas K, Emens JS. The phase shift hypothesis for the circadian component of winter depression. Dialogues Clin Neurosci (2007) 9(3):291-300.

53. Sprouse J, Braselton J, Reynolds L. Fluoxetine modulates the circadian biological clock via phase advances of suprachiasmatic nucleus neuronal firing. Biol Psychiatry (2006) 60(8):896-9. doi:10.1016/j.biopsych.2006.03.003

54. Terman M, Jiuan Su T. Circadian rhythm phase advance with dawn simulation treatment for winter depression. J Biol Rhythms (2010) 25(4):297-301. doi:10.1177/0748730410374000

55. Arey RN, Enwright JF III, Spencer SM, Falcon E, Ozburn AR, Ghose S, et al. An important role for cholecystokinin, a CLOCK target gene, in the development and treatment of manic-like behaviors. Mol Psychiatry (2014) 19(3):400. doi:10.1038/mp.2013.12

56. Sidor MM, Spencer SM, Dzirasa K, Parekh PK, Tye KM, Warden MR, et al. Daytime spikes in dopaminergic activity drive rapid mood-cycling in mice. Mol Psychiatry (2015) 20(11):1479-80. doi:10.1038/mp.2015.8

57. Kuersten S, Goodwin EB. The power of the 3' UTR: translational control and development. Nat Rev Genet (2003) 4(8):626-37. doi:10.1038/nrg1125

Conflict of Interest Statement: The authors declare no conflicts of interest associated with this manuscript. This research was conducted in the absence of any commercial or financial relationships that could be construed as a potential conflict of interest.

Copyright (c) 2016 Ozburn, Purohit, Parekh, Kaplan, Falcon, Mukherjee, Cates and McClung. This is an open-access article distributed under the terms of the Creative Commons Attribution License (CC BY). The use, distribution or reproduction in other forums is permitted, provided the original author(s) or licensor are credited and that the original publication in this journal is cited, in accordance with accepted academic practice. No use, distribution or reproduction is permitted which does not comply with these terms. 